\title{
Effect of utilization of maize silage in moult inducing diets on performance, immune response and bone quality in laying hens
}

\author{
H. Ayasi ${ }^{1,3}$, B. Dastar', T. Ghoorchi', S.R. Hashemi' and A. Tabaraei² \\ ${ }^{1}$ Gorgan University of Agricultural Sciences and Natural Resources, Faculty of Animal Sciences \\ Basij Square, 49189-43464, Gorgan, Iran \\ ${ }^{2}$ Golestan University of Medical Sciences, Department of Microbiology and Immunology \\ Sari-Gorgan highway, 49341-74515, Gorgan, Iran
}

KEY WORDS: maize silage, moult, bone tissue, immune system, laying hen

Received: 19 February 2015

Revised: 10 November 2015

Accepted: 29 February 2016

${ }^{3}$ Corresponding author:

e-mail: hosein.ayasi65@yahoo.com

\begin{abstract}
The aim of the study was to evaluate the utilization of maize silage (MS) in moult induction and its effects on immune response and bone quality in laying hens. Laying hens were subjected to 1 of 6 treatments: full-fed (control; FF); total feed withdrawal (positive control for moult induction; FW); 100\% MS (M100); $90 \%$ MS + 10\% layer ration (LR) (M90); $80 \%$ MS + 20\% LR (M80); and 70\% MS + 30\% LR (M70). After 9 days body weight loss occurred in all moulting treatments. The examined treatments caused cessation of egg production on day 4 (M90), 5 (FW, M100) and 7 (M70, M80). On day 6 the heterophil :lymphocyte $(\mathrm{H}: \mathrm{L})$ ratio did not differ between all MS treatments and FF; however FW caused its increasing only in comparison to FF, M80 and M70. On day $9 \mathrm{H}: \mathrm{L}$ ratio for FF did not differ only from M70 and M90. Antibody production against sheep red blood cell was unaffected by all moulting treatments. The femur dry weight for FF did not differ from M70, M80, M100; however there was observed no difference between FW and M70, M90, M100. The treatments caused decrease of femur ash content in comparison to FF group (except M70) with the lowest value in FW. In conclusion, obtained data indicate that the use of MS mixed with LR results in moult induction. Likewise, it is suggested to use $70 \% \mathrm{MS}$ addition because of reduced moulting stress in birds and smaller losses of bone mineralization.
\end{abstract}

\section{Introduction}

Moulting in avian species is defined as the periodic shedding and replacement of feathers. For most wild species of birds and domestic hens it is also connected with reproductive rejuvenation in which egg production ceases and the reproductive tract regresses (Berry, 2003). The force moulting has been used by the industry to rejuvenate flocks for a second or third egg laying cycle to increase profits. At the end of the laying cycle, egg production and quality decline significantly, leading producers to induce moult for improving performance. After the moulting period, egg production and quality improve significantly when compared to the premoult period. There are several types of induced moulting programmes that are used in commercial egg industry. Typical moulting programmes involve 
a reduction in the hours of light and removal of feed until hen losses approximate $25 \%$ or more of the body weight (Davis et al., 2002).

However, feed removal programmes have received considerable attention related to the animal welfare issue (Bell, 2003) and food safety reasons in recent years (Ricke, 2003). Moulting by this method is very stressful and can increase susceptibility to some diseases such as salmonellosis. Some reaserchers have found that feed withdrawal can affect the different components of the immune system such as thymus (Brake et al., 1981) and spleen weights (Brake et al., 1985). It can also affect differential white blood cell counts mainly by increasing the heterophils and decreasing the lymphocyte number in blood (Soe et al., 2009). Moreover, the moult induced with feed withdrawal is a potential factor escalating structural bone loss in old laying hens. Several studies have indicated that feed removal greatly influences bone quality in laying hens (Park et al., 2004). Therefore, alternative moulting techniques that would reduce or eliminate fasting are evaluated.

Alternative methods usually induce moult with the use of dietary manipulations to create the imbalance of a particular nutrient or nutrients (Berry and Brake, 1985). Many alternative methods have been studied to replace the feed removal programme. However some of them, which have yielded inconsistent results, are expensive and can cause negative forms of behaviour such as cannibalistic pecking (Webster, 2003; Biggs et al., 2004). Over the last few years, the ad libitum feeding of lucerne (Donalson et al., 2005) or fungus myceliated meal (Willis et al., 2009) and replacing a part of conventional laying hen diets with tomato pomace and safflower meal (Patwardhan et al., 2011) for 9 days were identified as alternative methods for moult induction.

Maize silage (Zea mays) is a fermented feed since it has an optimum level of short-chain fatty acids (SCFA) such as lactic acid. These weak organic acids can lower $\mathrm{pH}$ of the gut environment below the value that is essential for the pathogenic bacteria survival (Steenfeldt et al., 2007) and normal microflora improvement. The improvement of microflora with increased Lactobacilli and Bifidobacteria colonisations can modify the host's immune system. Moreover, SCFA are rapidly absorbed from the small intestinal tract and colon, stimulating electrolyte (such as $\mathrm{Ca}$ ) and water absorption within the intestinal tract (Chichlowski et al., 2007). Steenfeldt et al. (2007) reported that laying hens subjected with supplemental maize silage in diet ate approximately $60 \mathrm{~g}$ of maize silage per day. Accordingly, the current study was designed to evaluate the potential of maize silage as a single dietary source or as a component in mixture with layer ration for moult induction and its effects on immune parameters and bone quality parameters in laying hens.

\section{Material and methods}

The present study was conducted on the research farm of the Faculty of Animal Science, Gorgan University of Agricultural Sciences and Natural Resources.

Ninety-six 88-week old Single Comb White Leghorn hens, commercial hybrid line Lohman (LSL), were obtained from a local commercial layer farm. The hens were randomly allocated into 24 cages, 4 hens in each. Hens were allowed a week for acclimatization. During this time hens were fed a complete layer ration and were allowed full access to water. The lighting programme comprised $16 \mathrm{~h}$ of light and $8 \mathrm{~h}$ of dark (16L:8D). During the aacclimatization period, egg production was monitored to ensure that all hens were healthy and actively producing.

After acclimatization, all hens were randomly placed in 4 replicate cage groups with 4 hens in each cage, and assigned to the following treatments: fullfeed $(100 \%$ layer ration, $\mathrm{FF})$; total feed withdrawal (a positive control for moult induction; FW); 100\% maize silage (M100); 90\% maize silage with 10\% layer ration (M90); $80 \%$ maize silage with 20\% layer ration (M80); and 70\% maize silage with $30 \%$ layer ration (M70). Layer ration was a diet commonly used in commercial laying hen farms in Iran (Table 1). Commencing from day 1, feed

Table 1. Composition of commercial layer ration, $\mathrm{g} \cdot \mathrm{kg}^{-1}$

\begin{tabular}{ll}
\hline Ingredients & Commercial layer ration \\
\hline Yellow maize & 112.5 \\
Soyabean meal & 228.4 \\
Wheat & 535 \\
Dicalcium phosphate & 17 \\
Oyster shell & 45 \\
Calcium carbonate & 50 \\
NaCl & 3 \\
Vitamin premix & 3.5 \\
Mineral premix & 3.5 \\
DL-Methionine & 0.75 \\
L-Lysine $_{\text {Vitamin } \mathrm{D}_{3}}$ & 0.35 \\
\hline
\end{tabular}

${ }^{1}$ vitamin premix provided per kg of diet: IU: vit. A 29750, vit. $D_{3} 8750$, vit. $E 38.5$; mg: vit. $K_{3} 7.7$, vit. $B_{1} 5.17$, vit. $B_{2} 14$, niacin 27.44 , pantothenic acid 112.27 , vit. $B_{6} 8.62$, folic acid 0.385 , vit. $B_{12} 0.035$; ${ }^{2}$ mineral premix provided per kg of diet: mg: Mn 260, Fe 262, Zn 226.36, Cu 21,13 , Se 0.7 
was withdrawn or hens received their respective moulting diets for 9 days. Also the light programme was changed to $8 \mathrm{~L}: 16 \mathrm{D}$ photoperiod. Maize silage used for the experiment was provided daily in the form of chopped pieces (about $2 \mathrm{~cm}$ ) and mixed with the complete layer ration. All hens were allowed ad libitum access to water and their respective diets.

All hens were weighed individually at the beginning and the last day of the experiment and percentage of body weight loss (BWL) was calculated. Feed intake, mortality and egg production were recorded daily. Egg production percentage was calculated on a hen-day basis. At the end of the moulting procedure, 2 hens per replicate were slaughtered, and the ovary, oviduct, liver and spleen were excised and weighed. Moreover, right femur was collected to evaluate bone quality parameters as bone dry weight, ash content (Zhang and Coon, 1997). The bones were cleaned of attached tissues, dried at $100{ }^{\circ} \mathrm{C}$ for $24 \mathrm{~h}$ and weighed. The bones were subsequently ashed at $600{ }^{\circ} \mathrm{C}$ overnight, cooled in a desiccator and the obtained ash was weighed.

Antibody production against sheep red blood cells (SRBC) was measured in 2 hens in each replicate at the beginning of the experiment (day 2), and at day 9 following the start of the moulting programme. Hens were intramuscularly injected with $0.1 \mathrm{ml}$ of $0.25 \%$ SRBC in $0.9 \%$ saline (Onbaşilar and Erol, 2007). Circulating anti-SRBC antibody titers were determined by the micro haemagglutination technique. Differential counts of the white blood cells were measured from 2 other hens in each replicate at the day 2, 6 and 9 following the start of the moulting programme. For differential counts, a total of 100 cells were counted, once on each slide, using a light microscope at $\times 1000$ magnification (Olympus CX31; Olympus Company, Tokyo, Japan). The heterophils to lymphocytes ratio was determined. Also, serum samples were obtained on day 9 to evaluate blood calcium level using commercial kit (cresolphethalein copmplexone method, Calcium Kit - Cat. No. 50820125; Pishtaz Teb Company, Tehran, Iran).

\section{Statistical analysis}

A randomized complete block with 6 treatments and 4 blocks was employed. All statistical analyses were subjected to analysis of variance (ANOVA) using GLM procedure of SAS software (SAS Institute Inc., 2005). When the influence of treatment was stated by ANOVA test, Tukey's post-hoc test was applied to compare means with each other. Treatment means differed significantly at $P \leq 0.05$.

\section{Result and discussion}

Feed intake. There was observed the influence $(P<0.05)$ of treatment on feed intake (Table 2). Control FF hens exhibited the greatest feed intake among other birds. Feed intake by hens from M90, M80 and M70 treatments was similar, whereas by hens in M100 treatment was significantly lower. The reduction in feed consumption is a primary factor for moult induction so all examined treatments satisfied this condition. The observed feed intake reduction could be due to several factors such as an appetite suppression in conjunction with the natural moulting process (Mrosovsky and Sherry, 1980) and a decreased feeding stimulation with reduced daylight hours (Andrews et al., 1987). On the other hand, the increased percentage of maize silage in the diet tended to decrease feed consumption. Maize silage contains high level of fibre which is characterised by a slow passage rate in the guts and might have influenced feed intake causing a feeling of satiety and thus refraining hens from eating (Son et al., 2002; Steenfeldt et al., 2007).

Body and organ weights. No significant difference in initial body weight $(\mathrm{BW})$ was found among all experimental groups. All moulting inducing treatments caused an increased $(P<0.05)$ BW loss (BWL; expressed in $g$ or as a percentage of the initial $\mathrm{BW}$ ) in comparison to $\mathrm{FF}$ treatment (Table 2). No significant difference in BWL was found among all moult inducing treatments (FW, M100, M90, M80 and M70). BWL was shown to be directly related to the post-moult performance. In order to optimize post-moult performance, a BWL of $25-30 \%$ should be achieved (Baker et al., 1983). In the present study laying hens in moulting

Table 2. Effect of treatments on body weight (BW) and feed intake during the 9-day moulting programme

\begin{tabular}{|c|c|c|c|c|}
\hline \multirow{2}{*}{ Treatment $^{1}$} & Initial BW, & BW loss, & \multirow{2}{*}{$\begin{array}{l}\% \text { BW } \\
\text { loss }\end{array}$} & \multirow{2}{*}{$\begin{array}{l}\text { Feed intake, } \\
\text { g per bird }\end{array}$} \\
\hline & \multicolumn{2}{|c|}{$\mathrm{g}$} & & \\
\hline $\mathrm{FF}$ & 1783.4 & $119^{b}$ & $6.17^{b}$ & $889.8^{a}$ \\
\hline FW & 1786.4 & $601^{a}$ & $33.63^{a}$ & - \\
\hline M100 & 1741.8 & $614^{a}$ & $34.17^{a}$ & $75.2^{c}$ \\
\hline M90 & 1799.2 & $554^{a}$ & $30.51^{a}$ & $187.3^{b}$ \\
\hline M80 & 1749.3 & $502^{a}$ & $28.58^{a}$ & $213.1^{b}$ \\
\hline M70 & 1834.5 & $539^{a}$ & $29.31^{a}$ & $225.3^{b}$ \\
\hline SEM & 86.71 & 88.33 & 4.16 & 26.8 \\
\hline$P$-value & 0.71 & 0.0001 & 0.0001 & 0.0001 \\
\hline
\end{tabular}

${ }^{1} \mathrm{FF}$ - commercial layer diet; FW - total feed withdrawal; M100 - 100\% maize silage; M90 - 90\% maize silage and 10\% layer diet; M80 - 80\% maize silage and $20 \%$ layer diet; M70 - $70 \%$ maize silage and $30 \%$ layer diet; ${ }^{a b c}$ - means within a column with no common superscripts are significantly different $(P<0.05)$ 
Table 3. Effect of treatments on organs weights, \% body weight

\begin{tabular}{llllll}
\hline Treatment $^{1}$ & Liver & Spleen & Heart & Oviduct & Ovary \\
\hline FF & $2.58^{\mathrm{a}}$ & $0.090^{\mathrm{b}}$ & 0.49 & $3.88^{\mathrm{a}}$ & $2.63^{\mathrm{a}}$ \\
FW & $1.55^{\mathrm{b}}$ & $0.112^{\mathrm{ab}}$ & 0.46 & $1.47^{\mathrm{b}}$ & $0.84^{\mathrm{b}}$ \\
M100 & $1.66^{\mathrm{b}}$ & $0.130^{\mathrm{a}}$ & 0.50 & $1.58^{\mathrm{b}}$ & $0.9^{\mathrm{b}}$ \\
M90 & $1.77^{\mathrm{b}}$ & $0.113^{\mathrm{a}}$ & 0.46 & $1.45^{\mathrm{b}}$ & $0.86^{\mathrm{b}}$ \\
M80 & $1.63^{\mathrm{b}}$ & $0.107^{\mathrm{ab}}$ & 0.49 & $1.46^{\mathrm{b}}$ & $0.75^{\mathrm{b}}$ \\
M70 & $1.75^{\mathrm{b}}$ & $0.108^{\mathrm{a}}$ & 0.49 & $1.65^{\mathrm{b}}$ & $0.91^{\mathrm{b}}$ \\
SEM & 0.09 & 0.007 & 0.02 & 0.17 & 0.16 \\
$P$-value & 0.0001 & 0.01 & 0.73 & 0.0001 & 0.0001
\end{tabular}

${ }^{1}$ see Table 2; ab - means within a column with no common superscripts are significantly different $(P<0.05)$

treatments showed from $28-34 \%$ BWL. Control FF hens had higher $(P<0.05)$ ovary, oviduct and liver weight than hens from all other moulting treatments (Table 3). No significant difference in reproductive organs and liver weight was found between FW and all other moulting treatments with different level of maize silage. Brake and Thaxton (1979) reported that regression of the ovary is the most important factor for moulting induction because the loss of reproductive weight is linked to the overall rejuvenation process. Regression of the ovary reduces the function of the ovary causing reduction of steroid hormones (oestrogen, progesterone) release. Berry and Brake (1985) reported that the liver weight loss is due to oestrogen-dependent egg component synthesis, which is dependent on stimulation from ovarian steroids. Moreover, they reported that liver weight loss indicates a loss of hepatic energy storage (glycogen, lipids). The obtained results showed that higher energy concentration due to increased percentage of layer ration in moulting treatments did not influence liver weight loss in moulting hens. Only M100 and M90 treatment hens had higher spleen weight in comparison to FF treatment hens, but did not differ from other with moult induced hens. In view of the observed weight differences, the spleen weight is not considered as a critical factor to this moult induction study as was reflected in the antibody titer. No difference between groups was observed in case of heart weight.

Egg production. There was observed the influence of treatment on hen-day egg production percentage $(P<0.05)$ and number of day to zero egg production $(P<0.05)$ (Table 4$)$. The addition of maize silage as well as feed withdrawal decreased egg production in comparison to control group. Egg production ceased completely in all moulting treatments. M90 treatment caused the earliest cessation of egg production after 4 days. The M100 treatment reached the zero egg production at the same time as FW group - after 5 days. Both M70 and M80 caused
Table 4. Effect of treatments on egg production and number of days to zero egg production

\begin{tabular}{lll}
\hline Treatment $^{1}$ & Egg production, \% & $\begin{array}{l}\text { Number of days to zero } \\
\text { egg production }\end{array}$ \\
\hline FF & $40.97^{\mathrm{a}}$ & - \\
FW & $17.36^{\mathrm{b}}$ & $5^{\mathrm{b}}$ \\
M100 & $21.52^{\mathrm{b}}$ & $5^{\mathrm{b}}$ \\
M90 & $20.36^{\mathrm{b}}$ & $4^{\mathrm{b}}$ \\
M80 & $26.15^{\mathrm{b}}$ & $7^{\mathrm{a}}$ \\
M70 & $27.31^{\mathrm{b}}$ & $7^{\mathrm{a}}$ \\
SEM & 3.31 & 1 \\
P-value & 0.002 & 0.01
\end{tabular}

${ }^{1}$ see Table 2; ${ }^{\text {ab }}$ - means within a column with no common superscripts are significantly different $(P<0.05)$

cessation of egg production on day 7. Egg production ceased simultaneously with feed intake reducction in moulted treatments. Lower percentage of maize silage in M70 and M80 treatments tended to increase energy consumption rate causing later egg production rest in comparison to treatments based on 90 or $100 \%$ of maize silage.

Heterophil to lymphocyte (H:L) ratio and immunity response to sheep red blood cells (SRBC). It was observed no significant difference in H:L ratio between treatments (Table 5) at the beginning of the experiment (day 2). On day 6 of the experiment, the $\mathrm{H}: \mathrm{L}$ ratio was significantly higher in $\mathrm{FW}$ than in FF, M80 and M70 treatments. No significant difference was found between moulting treatments with maize silage and FF treatment. On day 9 of the experiment, the $\mathrm{H}$ :L ratio for $\mathrm{FW}$ treatment was significantly higher than for FF and M70 treatments but did not differ from other treatments. Physiological parameters of stress in poultry such as H:L ratio and suppression of humoral immunity are used for assessing welfare in different moulting programmes. The obtained results showed that maize silage

Table 5. Effect of treatments on heterophil:lymphocyte $(\mathrm{H}: \mathrm{L})$ ratio and antibody production against sheep red blood cells (SRBC)

\begin{tabular}{lllllll}
\hline \multirow{2}{*}{ Treatment $^{1}$} & \multicolumn{2}{l}{$\mathrm{H}: \mathrm{L}$ ratio, day } & & \multicolumn{2}{c}{ SRBC $^{2}$, day } \\
\cline { 2 - 4 } & 2 & 6 & 9 & & 9 \\
\hline FF & 0.09 & $0.13^{\mathrm{b}}$ & $0.10^{\mathrm{c}}$ & & 1.25 & 2.75 \\
FW & 0.13 & $0.27^{\mathrm{a}}$ & $0.20^{\mathrm{a}}$ & & 1.62 & 2.60 \\
M100 & 0.14 & $0.22^{\mathrm{ab}}$ & $0.18^{\mathrm{ab}}$ & & 1.00 & 4.00 \\
M90 & 0.09 & $0.19^{\mathrm{ab}}$ & $0.17^{\mathrm{abc}}$ & & 1.33 & 2.66 \\
M80 & 0.14 & $0.18^{\mathrm{b}}$ & $0.18^{\mathrm{ab}}$ & & 1.57 & 2.80 \\
M70 & 0.09 & $0.14^{\mathrm{b}}$ & $0.12^{\mathrm{bc}}$ & & 1.00 & 3.16 \\
SEM & 0.02 & 0.02 & 0.02 & & 0.33 & 0.77 \\
P-value & 0.21 & 0.02 & 0.02 & 0.33 & 0.55
\end{tabular}

${ }^{1}$ see Table 2; ${ }^{2}$ values are $\log _{2}$ of reciprocal dilution of antibody titer against SRBC; abc - means within a column with no common superscripts are significantly different $(P<0.05)$ 
addition did not increased $\mathrm{H}: \mathrm{L}$ ratio in comparison to control group after 6 days; however after 9 days the difference was observed between FF and M100 and M80. Davis et al. (2000) showed that H:L ratio remained consistent with age until the moult induction with feed withdrawal and then was significantly increased. Also, they reported that increased $\mathrm{H}: \mathrm{L}$ ratio during induced moult in laying hens is most likely related to the adaptation to changes in metabolic demands caused by physiological stress. The results observed in this study would indicate that moult induced with maize silage causes lower stress in hens than moult induced with feed withdrawal. No significant difference was observed between any of the treatments at any time periods in antibody production against SRBC. Such results are in agreement with the findings of Alodan and Mashaly (1999) who showed that different moult inducing programmes did not adversely affect antibody production against SRBC.

Bone parameters. The femur dry weight of hens from the FF treatment (Table 6) was significantly greater than one observed for FW and M90 treatment hens $(P<0.05)$. Also a significant difference was stated between FW and M80 treatments, whereas no significant difference was observed between FW and other maize silage treatments. The moult inducing treatments (except M70) caused decrease of femur ash content in comparison to FF group with the lowest value in FW treatment. Calcium serum in hens was decreased $(P<0.05)$ by all moult inducing treatments in comparison to $\mathrm{FF}$ treatment. The skeletal fragility related to osteoporosis is a main problem in old laying hens that clearly influences egg production and shell quality. The moult induced with feed withdrawal is a potential factor exacerbating structural bone losses in older laying hens (Kim et al., 2005). The results of assessing femur bone quality in this experiment suggest

Table 6. Effect of treatments on right femur (RF) quality parameters

\begin{tabular}{lllll}
\hline Treatment & RFDW $^{2}, g$ & $\begin{array}{l}\text { RF ash, } \\
\% \text { RFDW }\end{array}$ & $\begin{array}{l}\text { RFDW, } \\
\% \mathrm{BW}^{3}\end{array}$ & $\begin{array}{l}\text { Ca in serum, } \\
\mathrm{mg} \cdot \mathrm{dl}^{-1}\end{array}$ \\
\hline FF & $4.91^{\mathrm{a}}$ & $65.98^{\mathrm{a}}$ & $0.26^{\mathrm{c}}$ & $15.78^{\mathrm{a}}$ \\
FW & $3.83^{\mathrm{c}}$ & $52.59^{\mathrm{c}}$ & $0.31^{\mathrm{b}}$ & $10.58^{\mathrm{b}}$ \\
M100 & $4.36^{\mathrm{abc}}$ & $59.19^{\mathrm{b}}$ & $0.37^{\mathrm{a}}$ & $10.76^{\mathrm{b}}$ \\
M90 & $3.94^{\mathrm{bc}}$ & $58.15^{\mathrm{b}}$ & $0.32^{\mathrm{ab}}$ & $9.97^{\mathrm{b}}$ \\
M80 & $4.61^{\mathrm{ab}}$ & $59.36^{\mathrm{b}}$ & $0.36^{\mathrm{ab}}$ & $10.23^{\mathrm{b}}$ \\
M70 & $4.23^{\mathrm{abc}}$ & $60.87^{\mathrm{ab}}$ & $0.33^{\mathrm{ab}}$ & $10.37^{\mathrm{b}}$ \\
SEM & 0.26 & 0.02 & 0.02 & 0.70 \\
$P$-value & 0.04 & 0.02 & 0.02 & 0.001 \\
\hline
\end{tabular}

${ }^{1}$ see Table $2 ;{ }^{2}$ RFDW - RF dry weight; ${ }^{3} \mathrm{BW}$ - body weight; ${ }^{\text {abc }}$ - means within a column with no common superscripts are significantly different $(P<0.05)$ that hens lose a substantial amount of bone minerals during moult but this loss was lower in maize silage moulted hens than that of the FW moulted hens. Świątkiewicz et al. (2010) indicated that the addition of short chain organic acids to the diet for laying hens significantly improved bone quality. They reported that this influence can be probably attributed to improved availability of $\mathrm{Ca}$ and $\mathrm{P}$ due to a decrease in $\mathrm{pH}$ value in the upper part of the intestine and to the stimulating effect of organic acids on the villus height.

\section{Conclusions}

The utilization of maize silage-based moult inducing diets could decrease body weight and cease egg production similarly to conventional total feed withdrawal moulting programme. Due to this fact, the maize silage-based treatments appear to be a viable alternative to the conventional feed withdrawal. Likewise, it is suggested to use $70 \%$ maize silage addition because of reduced moulting stress in birds and smaller losses of bones mineralization.

\section{References}

Alodan M.A., Mashaly M.M., 1999. Effect of induced molting in laying hens on production and immune parameters. Poultry Sci. 78, 171-177

Andrews D.K., Berry W.D., Brake J., 1987. Effect of lighting program and nutrition on reproductive performance of molted single comb White Leghorn hens. Poultry Sci. 66, 1298-1305

Baker M., Brake J., McDaniel G.R., 1983. The relationship between body weight loss during an induced molt and post molt egg production, egg weight, and shell quality in caged layers. Poultry Sci. 62, 409-413

Bell D.D., 2003. Historical and current molting practices in the U.S. table egg industry. Poultry Sci. 82, 965-970

Berry W.D., 2003. The physiology of induced molting. Poultry Sci. 82 , 971-980

Berry W.D., Brake J., 1985. Comparison of parameters associated with molt induced by fasting, zinc and low dietary sodium in caged layers. Poultry Sci. 64, 2027-2036

Biggs P.E., Persia M.E., Koelkebeck K.W., Parsons C.M., 2004. Further evaluation of nonfeed removal methods for molting programs. Poultry Sci. 83, 745-752

Brake J.T., Berry W.D., Thaxton P., 1985. Cellular changes in the spleen during an induced molt. Poultry Sci. 64, 1031-1034

Brake J.T., Morgan G.W., Thaxton P., 1981. Recrudescence of the thymus and repopulation of lymphocytes during an artificially induced molt in the domestic chicken: Proposed model system. Develop. Comp. Immunol. 5, 105-112

Brake J., Thaxton P., 1979. Physiological changes in caged layers during a forced molt. 2. Gross changes in organs. Poultry Sci. $58,707-716$

Chichlowski M., Croom J., McBride B.W., Havenstein G.B., Koci M.D., 2007. Metabolic and physiological impact of probiotics or direct-fed-microbials on poultry: a brief review of current knowledge. Int. J. Poultry Sci. 6, 694-704 
Davis A.J., Lordelo M.M., Dale N., 2002. Use of cottonseed meats in molting programs. J. Appl. Poultry Res. 11, 175-178

Davis G.S., Anderson K.E., Carroll A.S., 2000. The effects of longterm caging and molt of single comb White Leghorn hens on herterophil to lymphocyte ratios, corticosterone and thyroid hormones. Poultry Sci. 79, 514-518

Donalson L.M., Kim W.K., Woodward C.L., Herrera P., Kubena L.F., Nisbet D.J., Ricke S.C., 2005. Utilizing different ratios of alfalfa and layer ration for molt induction and performance in commercial laying hens. Poultry Sci. 84, 362-369

Kim W.K., Donalson L.M., Herrera P., Kubena L.F., Nisbet D.J., Ricke S.C., 2005. Comparisons of molting diets on skeletal quality and eggshell parameters in hens at the end of the second egg-laying cycle. Poultry Sci. 84, 522-527

Mrosovsky N., Sherry D.F., 1980. Animal anorexias. Science 207, 837-842

Onbaşilar E.E., Erol H., 2007. Effects of different forced molting methods on postmolt production, corticosterone level, and immune response to sheep red blood cells in laying hens. J. Appl. Poultry Res. 16, 529-536

Park S.Y., Kim W.K., Birkhold S.G., Kubena L.F., Nisbet D.J., Ricke S.C., 2004. Induced molting issues and alternative dietary strategies for the egg industry in the United States. World Poultry Sci. J. 60, 196-209

Patwardhan D.S., King A.J., Mireles A., 2011. Tomato pomace and safflower meal as ingredients in non-feed-removal molt diets. J. Appl. Poultry Res. 20, 291-302
Ricke S.C., 2003. The gastrointestinal tract ecology of Salmonella enteritidis colonization in molting hens. Poultry Sci. 82, 1003-1007

SAS Institute Inc., 2005. SAS User's Guide: Statistics. Version 9.1. Cary, NC (USA)

Soe H.Y., Yayota M., Ohtani S., 2009. Effects of molt-induction period on induction of molt and post-molt performance in laying hens. J. Poultry Sci. 46, 203-211

Son J.H., Ragland D., Adeola O., 2002. Quantification of digestive flow into the caeca. Brit. Poultry Sci. 43, 322-324

Steenfeldt S., Kjaer J.B., Engberg R.M., 2007. Effect of feeding silages or carrots as supplements to laying hens on production performance, nutrient digestibility, gut structure, gut microflora and feather pecking behavior. Brit. Poultry Sci. 48, 454-468

Świątkiewicz S., Koreleski J., Arczewska A., 2010. Effect of organic acids and prebiotics on bone quality in laying hens fed diets with two levels of calcium and phosphorus. Acta Vet. Brno 79, 185-193

Webster A.B., 2003. Physiology and behavior of the hen during induced molt. Poultry Sci. 82, 992-1002

Willis W.L., Isikhuemhen O.S., Allen J.W., Byers A., King K., Thomas C., 2009. Utilizing fungus myceliated grain for molt induction and performance in commercial laying hens. Poultry Sci. 88, 2026-2032

Zhang B., Coon C.N., 1997. The relationship of various tibia bone measurements in hens. Poultry Sci. 76, 1698-1701 